\section{COMPARING THE RIGIDITY OF THE PRESTRESSED AND NON-PRESTRESSED FOUNDATION}

\author{
Jana Labudkova*, Radim Cajka ${ }^{a}$
}

Department of Structures, Faculty of Civil Engineering, VŠB Technical University of Ostrava, Ludvika Podeste 1875/17, 70833 Ostrava-Poruba, CZECH REPUBLIC
Article history

Received

5 June 2015

Received in revised form

9 September 2015

Accepted

10 December 2015

*Corresponding author jana.labudkova@vsb.cz

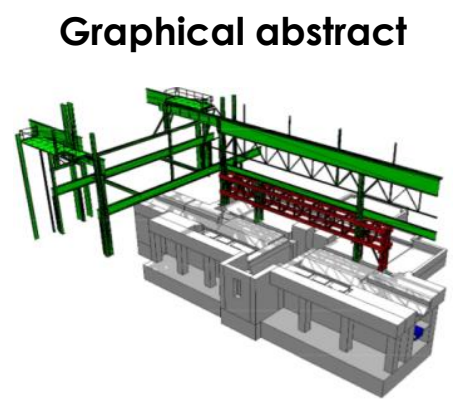

\begin{abstract}
If compared with reinforced concrete, the prestressed concrete is able to resist higher loads before cracks develop. As cracks reduce considerably rigidity of the element, the prestressed element can be regarded as rather rigid. The article compares the rigidity of the prestressed and non-prestressed foundations in two axes. Prestressed and non-prestressed variant is made for foundation structure of the rolling device in the Block Mill. A parametric study was created for investigation of impacts of the prestress on the foundation height. The savings of the concrete due to prestressing was also observed.
\end{abstract}

Keywords: Subsoil-structure interaction, FEM analyses, prestressed foundations, post-tensioned foundations, strengthening machine foundations

(C) 2016 Penerbit UTM Press. All rights reserved

\subsection{INTRODUCTION}

When prestressing concrete, internal forces are intentionally applied into an element which compensate, completely or partly, the stress resulting from the internal load. If compared with reinforced concrete, the prestressed concrete is able to resist higher loads before cracks develop. When the external load is applied and tension in the stress is transferred, it is first the tension force which takes out of the concrete the pressure reserve which was introduced there before start of the loading process. As cracks reduce considerably rigidity of the element, the prestressed element can be regarded as rather rigid. Considering the ultimate condition of strain, it is possible then to design the prestressed structures with a small height of the cross-section. This reduces the own weight and saves materials. The prestressed concrete has been employed more and more frequently in the design and construction of foundation structures and industrial floors. Use of prestressed foundations in construction is also discussed in [1, 2, 3, 4, 5] and its interaction with subsoil in $[6,7,8,9]$.

Heavy industry, industrial plants and technology facilities use really big manufacturing units or assemblies with the weight of tens of tons. In case of rotary kilns, the weight can reach hundreds of tons. During the production process, those units move, creating, in addition to considerable static effects, big dynamic effects. This is, for instance, the case of crushers, separators, mills, drying units, rotary kilns or other facilities $[10,11,12,13,14,15]$. Such facilities are designed to work correctly for as many as dozen of years - sometimes they should work throughout the service life of the entire industrial plant. That is why a particular attention should be paid to foundations of such structures. In off-peak production periods, maintenance and capital repair of facilities are performed. When repairing the facilities, parts which have become more or less worn are replaced with new ones. Defects or extensive wear of the facilities often result from failures of reinforced concrete in the plant foundation or from failures in subsoil. When repairing, refurbishing or reconstructing the industrial plants or technology facilities, a particular attention should be paid to the foundation structures and subsoil. Interaction between foundation and subsoil is discussed also in $[16,17,18,19]$.

The foundations can be exposed, in addition to dynamic effects and vibrations from the facility, to 
aggressive substances if oil or chemicals leak from the facility. This may cause the concrete to degrade which, in turn, results in failures of the concrete structure.

Industrial facilities often face failures of the reinforced concrete foundation which is loaded dynamically by a rotating machine. Such failures typically result in cracks and failures of any of the foundation cross-section. Thus, a part of the foundation starts deviating, the rigidity goes down, geometry of the machine position is changing and an accident may occur - for instance, bearings may fail or malfunctions may occur in the machine.

Visualisation in Figure 1 shows the foundation structure of the rolling device in the Block Mill I in Třinecké železárny a.s. In that case, the rigidity was compared for the foundation made form prestressed and non-prestressed concrete. The slab of the foundation structure is approximately a T-shape. The monolith foundation slab will be $2.0 \mathrm{~m}$ thick. It will be cast on site and connected with other vertical and horizontal structures which are needed for installation of the rolling mill (Figure 1).

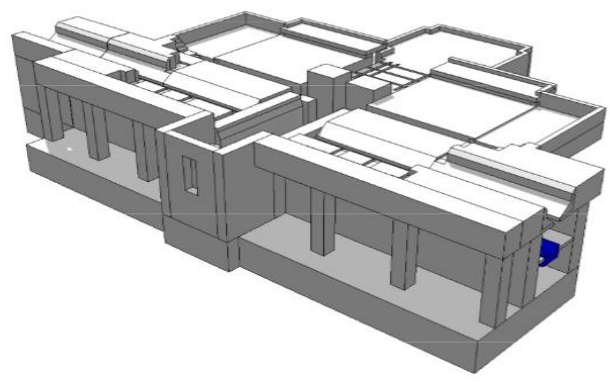

Figure 1 Visualisation of the foundation

\subsection{NUMERICAL ANALYSIS}

The article compares the rigidity of the prestressed and non-prestressed foundations in two axes which are normal to each other in the $X-X$ and $Y-Y$ cross-sections (Figure 2).

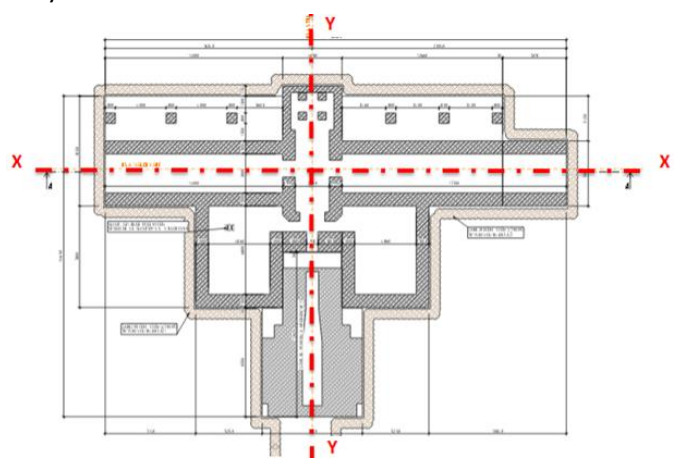

Figure 2 Cross-sections through the foundations in the direction of the $x$ and $y$ axes

The cross-sections are made in those parts of the foundation where the plant loads the foundation structure most. In the $y$-axis, the $Y$ - $Y$ cross-section crosses approximately the foundation axis (note: the foundation is not symmetrical by the axis). In the x-axis, the $X-X$ cross-section is made through the rolling axis (Figure 2).

The software used for the numerical analysis was Scia Engineer 15.0. The slab cross-section/the slab strip was modelled as a shell where the strip was $1 \mathrm{~m}$ wide and 2 $\mathrm{m}$ high. The slab strip was placed onto subsoil. The model was a one-parameter contact model of the subsoil: the Winkler's model of subsoil.

In Scia Engineer it is possible to use 2D support to model the Winkler's model. With that support, it is not an iteration calculation and the results depend on the selected subsoil parameters: $C_{1 x}, C_{1 y}, C_{1 z}, C_{2 x}, C_{2 y}$. It is $\mathrm{C}_{1 z}$ which plays the key role in the analysis and characterises the subsoil rigidity. The $C_{1 z}$ value can be obtained for that soil from the linear relationship (1), which is valid for the case of an elastic incompressible subsoil layer. Once the modulus of deformability of soil is introduced ( $E_{d e f}=15 \mathrm{MPa}$ ) and height of soil is specified $(h=2 \mathrm{~m})$, one obtains $C_{1 z}=7,5 \mathrm{MN} / \mathrm{m}^{3}$.

$$
C_{1 z}=\frac{E_{d e f}}{h}
$$

where

$\mathrm{C}_{1 z}$ the rigidity of subsoil in the vertical direction

Edef is the modulus of deformability of soil

$h \quad$ is the height of the soil layer with $E_{\text {def }}$

The geology of the soil was identified in a drill hole profile. There was a single layer, $2.0 \mathrm{~m}$ thick. Properties of the soil in that layer were defined using the Poisson coefficient $(v=0,3)$, modulus of deformability (Edef $=15 \mathrm{MPa})$ and volumentric load $\left(\gamma=22 \mathrm{kN} / \mathrm{m}^{3}\right)$. The corrective coefficient, $m=0.2$, was chosen pursuant to EC 7 [20].

The prestress can easily eliminate effects of the dead load. The loading of the structure was modelled, in the both cross-sections, in the vertical direction only because the calculation considered the dead load of the foundation caused from reinforced/prestressed concrete and considered also the vertical dead load caused by the fixed equipment installed on the site. Horizontal loads resulting from movements and operation of machines are random loads. They were not considered in calculation and in the parametric study which focused on impacts of the prestress on the foundation height. In case of the prestressed foundation, attention was also paid to bending moment loads which were represented by prestress loads - this means, by the prestress force applied onto the eccentricity towards the axis or centreline plane of the slab strip.

The load of the non-prestressed element resulting in strains $w_{0}$. Prestressing reduces the final strain in that element. This means that the prestress increases rigidity of the element which can be considered in calculation using the equivalent moment of inertia for the crosssection Jekv (2), [21]: 


$$
J_{E k v}=-\frac{m_{0, x}}{E\left(\frac{d^{2} w_{0, x}}{d x^{2}}+\frac{d^{2} w_{P, x}}{d x^{2}}\right)}
$$

The equation for calculation of the moment of inertia of a rectangular cross-section, $\mathrm{J}=\mathrm{bh}^{3} / 12$, can be used to calculate the equivalent height of the prestressed cross-section hekv (3), [21]:

$$
h_{E k v}=\sqrt[3]{-\frac{12 m_{0, x}}{b E\left(\frac{d^{2} w_{0, x}}{d x^{2}}+\frac{d^{2} w_{P, x}}{d x^{2}}\right)}}
$$

$$
\begin{aligned}
& \begin{array}{l}
\text { where } \\
m_{0, x}
\end{array} \begin{array}{l}
\text { is the specific bending moment of the non- } \\
\text { prestressed element in } x \text { (in this article, } x \text { is the } \\
\text { point of the maximum moment) }
\end{array} \\
& W_{0, x} \begin{array}{l}
\text { is the strain of a non-prestressed element in } x \\
W_{p, x}
\end{array} \\
& \begin{array}{l}
\text { is the strain of the element in } x \text { - caused by } \\
\text { single moments which characterise the } \\
\text { prestress }
\end{array} \\
& \text { is the modulus of elasticity of the concrete } \\
& b \quad \begin{array}{l}
\text { is the width of foundation }
\end{array}
\end{aligned}
$$

The specific bending moment $m_{0, x}$ in a nonprestressed element in $\mathrm{x}$ was calculated numerically using the Finite Element Method in a Scia Engineer model. The second derivation of the deflection (in the bracket for the denominator in (3)) gives the general bending moments, this means $m_{0, x}, m_{p, x}$, where $m_{p, x}$ is the specific bending moment in $\mathrm{x}$ which is caused by loads of single moments which characterise the prestress. A parametric study was created for investigation of impacts of the prestress on the foundation height.

\subsection{PARAMETRIC STUDY}

A parametric study was created for investigation of impacts of the prestress on the foundation height. Constant values in the parametric calculations were the bending moment mo,x of the non-prestressed element in $x$, the modulus of deformability of concrete $\mathrm{E}$ and the foundation width $\mathrm{b}$. Variables included the foundation height, the force induced by the prestress and location of the prestressing cable (eccentricity of the prestressing force). When placing the prestressing cable in the cross-section, $100 \mathrm{~mm}$ cover was kept at the lower edge of the foundation. This means that $m_{p, x}$ was variable in different calculations of the parametric study.

The parametric study was performed for two directions which were normal to each other and which were loaded most by the machines. In the $X-X$ and $Y-Y$ cross-sections, numerical solutions are available for the $1 \mathrm{~m}$ wide slabs (strips) (Figure 3).

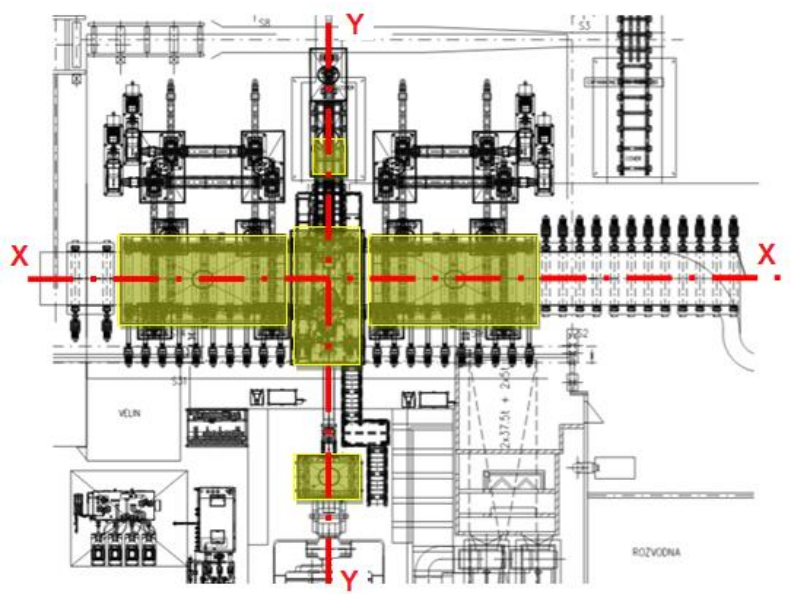

Figure 3 Dead load from the installed machines, $x-x$ and $y-y$

\subsection{Parametric Study in the Y-Y Cross-section}

The numerical analysis considered the load caused in the $Y$-Y cross-section by vertical forces (the dead load of the foundation and machines installed on the site). The load includes the dynamic coefficient.

The first loading state was caused by the dead load of the foundation. The second loading state was caused by the load of the installed machines (Figure 4):

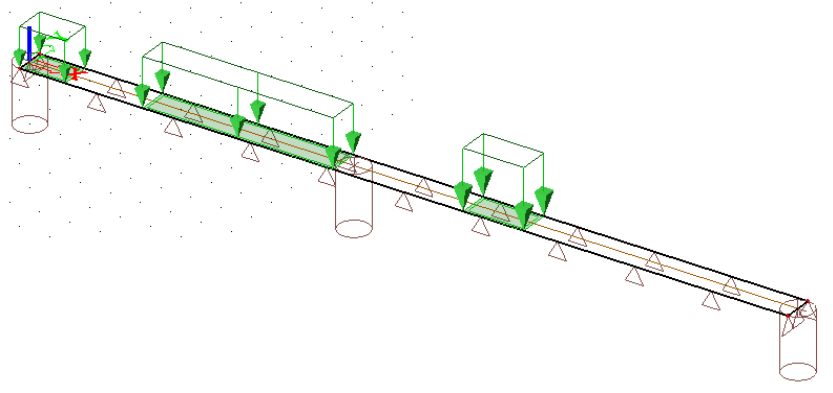

Figure 4 The first and second loading states, $Y-Y$

The prestressing states above were used to load the non-prestressed foundation. Then, the specific bending moment of the non-prestressed element mo,x was calculated. For the height $\mathrm{h}=2 \mathrm{~m}$ the maximum value of $\mathrm{mo}_{0, \mathrm{x}}=780.54 \mathrm{kNm} / \mathrm{m}$ (Figure 5).

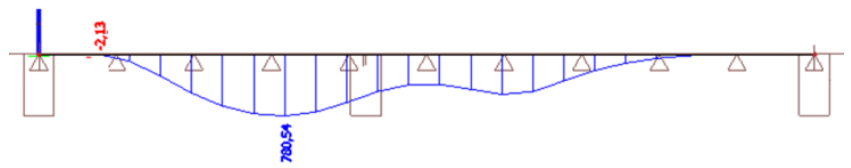

Figure $\mathbf{5}$ The specific bending moment of the non-prestressed element $m_{0, x}, Y-Y$ 
In case of the prestressed foundation, attention was also paid to bending moment loads (the third loading state) which were represented by prestress loads - this means, by the prestress force applied onto the eccentricity towards the axis or centreline plane of the slab strip.

\subsubsection{Comparing the Height of the Prestressed/non- prestressed Foundations in the $y$-axis}

The behaviour and values of the specific bending moments $\mathrm{m}_{\mathrm{x}, \mathrm{x}}$ in $\mathrm{x}$ are variable. They are caused by single moments and depend on the variable height of the foundation, $h$, and on prestressing forces. The following heights were chosen for the foundation: 2.0 $\mathrm{m}, 1.75 \mathrm{~m}, 1.50 \mathrm{~m}$ and $1.25 \mathrm{~m}$. The prestressing forces were chosen $250 \mathrm{kN}$ from the both ends of the strips and $500 \mathrm{kN}, 750 \mathrm{kN}$ and $1000 \mathrm{kN}$. By substitution in (3) one obtains the equivalent height hekv and the $h / h_{\text {ekv }}$ ratio. The chart in Figure 6 shows the relationship between the original foundation height $h$ and the equivalent foundation height hekv and the increase which depends on the prestressing force.

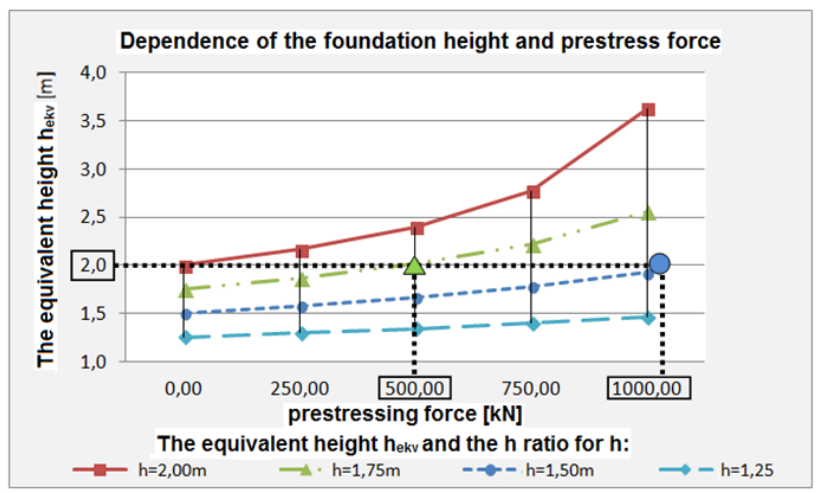

Figure 6 Foundation height and the prestress force; $h / h_{\text {ekv }} ; Y-Y$

Figure 7 shows the relationship between the foundation height and size of the prestressing force. It is obvious that the increasing height and increasing prestressing force result in the increasing foundation height hekv. The biggest deviation between the necessary foundation height of the prestressed/nonprestressed foundation exists with the highest foundation height $(2 \mathrm{~m})$ and the highest prestressing force $(1000 \mathrm{kN})$ because this maximum force is also applied with the biggest leverage/with the biggest eccentricity from the centreline plane of the foundation. Thus, the prestressing is most efficient.

Chart in Figure 7 also shows that the $2 \mathrm{~m}$ high nonprestressed foundation (where the prestressing force is $P=0 \mathrm{kN}$ ) can be replaced, for instance, with the foundation which is $1.75 \mathrm{~m}$ high and is prestressed with $500 \mathrm{kN}$ in both ends or with the foundation which is 1.50 $\mathrm{m}$ high and is prestressed with $1,000 \mathrm{kN}$ in both ends. With the prestressing force of $1,000 \mathrm{kN}$ it would be possible to save as much as 25 per cent of concrete.

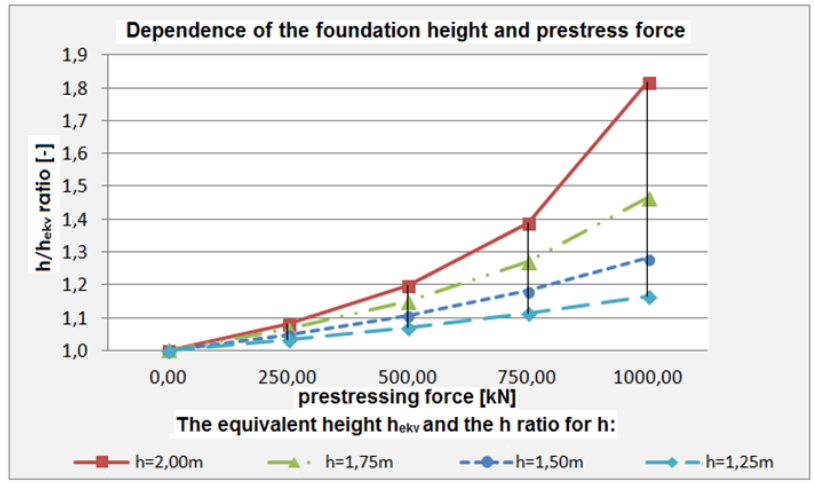

Figure 7 Height foundation and the prestress force

The prestress force and savings in the concrete might be even higher. Using (4) it is possible to obtain $\mathrm{P}_{\max }-$ the maximum force to prestress the concrete without crushing it. $\sigma_{\text {max }}$ is the maximum stress caused by the prestress force which is applied on the cross-section surface of concrete. It should not exceed the compressive strength of concrete, $\mathrm{f}_{\mathrm{cd}}$.

$$
\sigma_{\max }=\frac{P_{\max }}{A} \leq f_{c d}
$$

If the compressive strength of concrete is known (for the $\mathrm{C} 20 / 25$ concrete), the maximum prestress force is $P_{\max }=26.6 \mathrm{MN}$.

\subsection{Parametric study in the $\mathrm{X}-\mathrm{X}$ cross-section}

The numerical analysis considered the load caused in the $\mathrm{X}-\mathrm{X}$ cross-section by vertical forces (the dead load of the foundation and machines installed on the site). The load includes the dynamic coefficient.

The first loading state was caused by the dead load of the foundation. The second loading state was caused by the load of the installed machines (Figure 8):

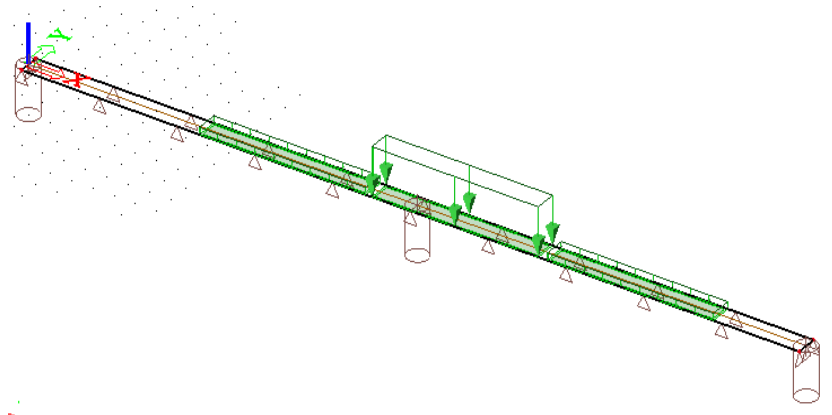

Figure $\mathbf{8}$ The first and second loading states, X-X

The prestressing states above were used to load the non-prestressed foundation. Then, the specific bending moment of the non-prestressed element mo,x was 
calculated. For the height $\mathrm{h}=2 \mathrm{~m}$ the maximum value of $\mathrm{m}_{0, \mathrm{x}}=2,278.24 \mathrm{kNm} / \mathrm{m}$ (Figure 9).

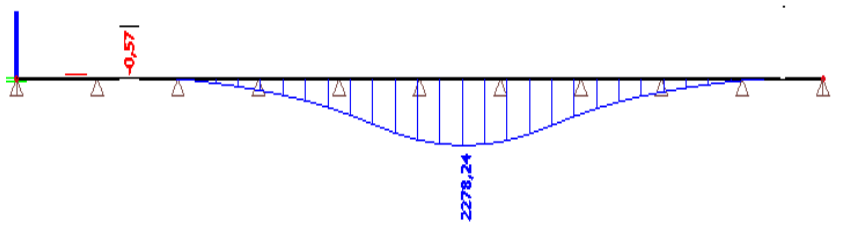

Figure 9 The specific bending moment of the non-prestressed element $m_{0, x}, X-X$

In case of the prestressed foundation, attention was also paid to bending moment loads (the third loading state) which were represented by prestress loads - this means, by the prestress force applied onto the eccentricity towards the axis or centreline plane of the slab strip.

\subsubsection{Comparing the Height of the Prestressed/non- prestressed Foundations in the $\mathrm{x}$-axis}

The behaviour and values of the specific bending moments $m_{P, x}$ in $x$ are variable. They are caused by single moments and depend on the variable height of the foundation, $h$, and on prestressing forces. The crosssection in the $x$-axis is longer than that in the $y$-axis and is subject to higher loads. The cross-section length in the $x$-axis is $36.38 \mathrm{~m}$ and the loaded created the specific bending moment of $m_{0, x}=2,278.24 \mathrm{kNm} / \mathrm{m}$. That is why the variable height of the foundation and prestress force was different in the parametric study than that in the $y$-axis. The foundation height and prestress force were monitored for $1,000 \mathrm{kN}, 2,000 \mathrm{kN}, 3,000 \mathrm{kN}$ and $4,000 \mathrm{kN}$. The values were compared in Figure 10 and Figure 11 with those existing the non-prestressed foundation - this means for the prestress force $=0 \mathrm{kN}$. The foundation height was $2.0 \mathrm{~m}, 1.80 \mathrm{~m}, 1.60 \mathrm{~m}$ and $1.40 \mathrm{~m}$. By substitution in (3) one obtains the equivalent height hekv and the $h / h_{\text {ekv }}$ ratio.

The chart in Figure 10 shows the relationship between the original foundation height $h$ and the equivalent foundation height hekv and the increase which depends on the prestressing force.

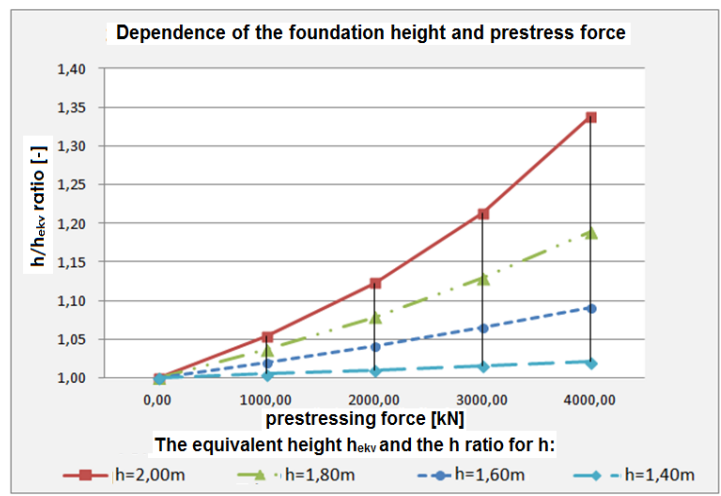

Figure 10 The foundation height and prestress force; $h / h_{e k v} ; X-X$
Figure 11 shows the relationship between the foundation height and size of the prestressing force. It is obvious that the increasing height and increasing prestressing force result in the increasing foundation height hekv. The biggest deviation between the necessary foundation height of the prestressed/nonprestressed foundation exists with the highest foundation height $(2 \mathrm{~m})$ and the highest prestressing force $(4,000 \mathrm{kN})$ because this maximum force is also applied with the biggest leverage/with the biggest eccentricity from the centreline plane of the foundation. Thus, the prestress is most efficient.

It follows from the chart that the $2 \mathrm{~m}$ high nonprestressed foundation (where the prestressing force is $\mathrm{P}=0 \mathrm{kN}$ ) can be replaced, for instance, with the foundation which is $1.80 \mathrm{~m}$ high and is prestressed with cca 2,500 kN in both ends. With the prestressing force of $2,500 \mathrm{kN}$ it would be possible to save as much as 10 per cent of concrete.

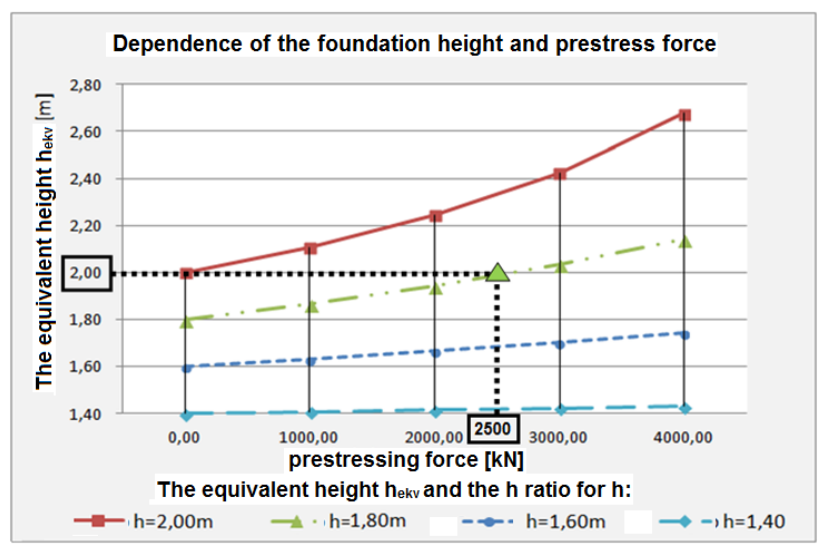

Figure 11 Height foundation and the prestress force

The prestress force and savings in the concrete might be even higher. Using (5) it is possible to obtain $P_{\max }$ the maximum force to prestress the concrete without crushing it. The maximum stress $\sigma_{\max }$ caused by the prestress force which is applied on the cross-section surface of concrete should not exceed the compressive strength of concrete, $\mathrm{f}_{\mathrm{cd}}$.

$$
\sigma_{\max }=\frac{P_{\max }}{A} \leq f_{c d}
$$

If the compressive strength of concrete is known (for the $\mathrm{C} 20 / 25$ concrete), the maximum prestress force is $P \max =26.6 \mathrm{MN}$.

\subsection{CONCLUSION}

The article compares the rigidity of the prestressed and non-prestressed foundations in two axes ( $x$ and $y$ ). Prestressed and non-prestressed variant is made for foundation structure of the rolling device in the Block Mill in Třinecké železárny a.s. 
The software used for the numerical analysis was Scia Engineer 15.0. The slab cross-section/the slab strip was modelled as a shell where the strip was $1 \mathrm{~m}$ wide and 2 $\mathrm{m}$ high. The slab strip was placed onto subsoil. The model was a one-parameter contact model of the subsoil: the Winkler's model of subsoil.

A parametric study was created for investigation of impacts of the prestress on the foundation height. Variables included the foundation height, the force induced by the prestress and location of the prestressing cable (eccentricity of the prestressing force).

It has been proven that the $2 \mathrm{~m}$ high non-prestressed foundation (where the prestressing force is $P=0 \mathrm{kN}$ ) can be replaced, for instance, with the foundation which is $1.75 \mathrm{~m}$ high and is prestressed with $500 \mathrm{kN}$ in both ends or with the foundation which is $1.50 \mathrm{~m}$ high and is prestressed with 1,000 kN in both ends. With the prestressing force of $1,000 \mathrm{kN}$ it would be possible to save as much as 25 per cent of concrete (for the crosssection y-y).

It has been proven that the $2 \mathrm{~m}$ high non-prestressed foundation (where the prestressing force is $P=0 \mathrm{kN}$ ) can be replaced, for instance, with the foundation which is $1.80 \mathrm{~m}$ high and is prestressed with cca 2,500 $\mathrm{kN}$ in both ends. With the prestressing force of $2,500 \mathrm{kN}$ it would be possible to save as much as 10 per cent of concrete (cross-section $\mathrm{x}-\mathrm{x}$ ).

The prestress force and savings in the concrete might be even higher. It is possible to use $P_{\max }$ - the maximum force to prestress the concrete without crushing it. It should not exceed the compressive strength of concrete, $\mathrm{f}_{\mathrm{cd}}$.

\section{Acknowledgement}

This paper was financially supported by the project of "The conceptual research and development 2015" in the Faculty of Civil Engineering, VŠB - Technical University of Ostrava.

\section{References}

[1] Feld, J., White, R. E. 1974. Prestressed Tendons In Foundation Construction. 25-32.

[2] Friedrich, T. 2004. Prestressed Foundations Slabs [Vorgespannte Bodenplatten-Ein Brachliegendes Potential]. Beton- Und Stahlbetonbau. 99(8): 641-651.

[3] Kiziriya, G. V., Dzhanelidze, S. H. A., Dzhobava, D. G. 1981. Use of Prestressed Foundations In Construction. Soil Mechanics and Foundation Engineering. 18(2): 47-48.

[4] 1982. Design and Construction of Post-Tensioned Slabs-OnGround, Post-Tensioning Institute, Arizona, 89.

[5] Mynarcik, P. 2015. The Subsidence Analysis of Experimental Post-Tensioned Concrete Slab Model In The Course Of the
Static Load Test, Applied Mechanics and Materials. 744-746: 1556-1559. Trans Tech Publications. Switzerland.

[6] Cajka, R. Mateckova, P. 2010. Comparison of Calculating Methods and Consequent Carrying Capacities Of PreStressed Precast Concrete Roof Purlin. Proceedings Of First International Workshop. Design of Concrete Structures Using. EN 1992-1-1. Prague. ISBN 978-80-01-04581-7, WOS: 000324078100017

[7] He, S. M., Yang, X. L., Zhou, Y.J. 2006. Analysis Of Interaction Of Prestressed Anchor Rope Foundation Beam And Foundation. Yantu Lixue/Rock and Soil Mechanics. 27(1): 8388.

[8] Stavridis, L. T. 2011. Prestressed Foundation Beams on Elastic Layered Soil Geotechnical and Geological Engineering. 29(4): 431-442.

[9] Tovsik, P. Y. E. 2009. The Vibrations and Stability Of A Prestressed Plate On An Elastic Foundation. Journal of Applied Mathematics and Mechanics. 73(1): 77- 87.

[10] Wang, S. Z. 2011. Development And Production Of Steel For 5000 M3 Blast Furnace Shell. Kang T'ieh/Iron And Steel. (Peking). 46(7):-99.

[11] Allahbakhshi, M., Sadeghi, H.: Behaviour Of Industrial Machinery Foundation On Prestressed Geogrid-Reinforced Embankment Over Soft Soil Under Static Load. Science Journal Of Energy Engineering. Doi: 10.11648/J.Sjee.20140206.11, ISSN: 2376-810X (Print); ISSN: 2376-8126 (Online).

[12] Cajka, R., Manasek, P. 2005. Building Structures In Danger Of Flooding. IABSE Conference On Role Of Structural Engineers Towards Reduction Of Powert. New Delhi, India, ISBN 385748-111-0.

[13] Gazetas, G. 1983. Analysis of Machine Foundation Vibrations: State Of The Art. Soil Dynamics And Earthquake Engineering. 2(1)

[14] Chasov, E. I. 1978. Strengthening Machine Foundations. Soil Mechanics and Foundation Engineering. 15(2): 100-103.

[15] Lundén, R., Kamph, E. 1982. Vibration Isolation Of A Damped Skeletal Machine Foundation-Theory And Experiment. The Journal Of The Acoustical Society Of America. 71 (3).

[16] Bespalova, E. I., Urusova, G. P. 2006. Contact Interaction Between Prestressed Laminated Shells Of Revolution And A Flat Foundation. International Applied Mechanics. 42(10): $1137-1144$

[17] Cajka, R. 2005. Soil-Structure Interaction In Case Of Exceptional Mining And Flood Actions. Improvement Of Buildings' Structural Quality By New Technologies. Proceedings Of The Final Conference Of COST Action C12. 369-376.

[18] Cajka, R., Janulikova, M., Mateckova, P., Stara, M. 2011.Modeling of Foundation Structure With Slide Joint With Temperature Dependant Characteristics. CC201: The Thirteenth International Conference on Civil, Structural And Environmental Engineering Computing. Chania, Crete, Greece, 6.9.-9.9. ISBN 978-1-905088-45-4.

[19] Labudkova, J. Cajka, R. 2014. Comparsion Of Measured Displacement Of The Plate In Interaction With The Subsoil And The Results Of 3D Numerical Model, Advanced Material Research. 1020: 204-209 (6 P), Trans Tech Publications, Switzerland, ISSN (Online) 1662-8985, ISSN (Print) 1022-6680.

[20] EN 1997-1. 2004. Eurocode 7: Geotechnical Design - Part 1: General Rules, 2004/18/EC.

[21] Sekanina, D., Cajka, R. 2009. Determination Of The Relative Stiffness Of The Subsoil And Prestressed Concrete Foundations, IDEAS 09: Integrated Design Of Advanced Structures. Proceedings Of Extended Abstracts, Specialist Conferences, VSB - Technical University Of Ostrava. 2009:121-122, 978-80-248-2091-0, (In Czech). 